\title{
FORMAS DE ESTRIBILLO EN LA POESÍA DE EMILIO PRADOS
}

\author{
FORMS OF REFRAIN IN \\ EMILIO PRADOS' POETRY
}

\author{
Mario García-PAgE \\ UNED (Madrid)
}

\begin{abstract}
Resumen: Un rasgo de la creación poética de Emilio Prados es el empleo del estribillo, un recurso característico de la poesía popular tradicional, en especial de la poesía de tipo paralelístico. El estribillo es no sólo un artificio de versificación, sino también un fenómeno de repetición de orden textual. El estribillo se manifiesta en Prados muy diversamente: repetición exacta / repetición inexacta o variable, estribillo exento o tipográficamente aislado / estribillo integrado (es decir, embutido en la estrofa), etc. Una de las principales formas de expresión del estribillo en Emilio Prados es la ruptura consciente en la última ocurrencia del estribillo en el cierre del poema (por ejemplo, mediante una variación léxica, gramatical o gráfica, o por la adición de un verso extraño).
\end{abstract}

Palabras clave: Estribillo, poesía paralelística, lenguaje literario, repetición.

Abstract: A feature of Emilio Prados' poetic creativity is the use of refrain, a characteristic resource within popular traditional poetry, particularly that of the in-parallel type. The refrain is not only a versification device but also a repetition phenomenon of a textual kind. It makes itself apparent in Prados' poetry in different ways: exact repetition / inexact or variable repetition, free or typo- 
graphically isolated refrain / integrated refrain (that is, the refrain included within a stanza), etc. The deliberate breaking which occurs at the end of a poem (for instance, because of some lexical, grammatical, or graphic modification, or the addition of a foreign line) is representative of some of the main formats the refrain takes on in Emilio Prados' poetry.

Key words: Refrain, in-parallel poetry, literary language, repetition. 


\section{Introducción: trazos generales de la poesía de Emilio Prados}

$\mathrm{U}$

Tn estudio de conjunto, de la obra lírica completa de Emilio Prados Such ${ }^{1}$, permite aventurar una serie de rasgos o propiedades del estribillo como artificio constructivo del discurso metrificado que podrían considerarse característicos del poeta malagueño, aunque no exclusivos pues también se advierten en otros escritores.

Una gran parte de la producción artística de Emilio Prados, precisamente la que entronca más firme y directamente con la poesía neo-popular, incorpora, con mayor o menor insistencia, el estribillo como constituyente estructural, entre otros mecanismos de repetición textual.

El estudio de conjunto desvela que el estribillo se manifiesta diversamente en la poesía de Emilio Prados, adoptando fórmulas muy variadas, algunas atípicas, netamente originales: de las formas más puras y obedientes con el modelo clásico de la canción popular tradicional ${ }^{2}$, que recogen los cancioneros medievales y los poetas de la Edad de Oro practicaron con soberbia maestría, a las formas más innovadoras, más irreverentes con dicho modelo, más del gusto de la poesía neopopular de corte estribillístico del siglo xx. El estribillo que sigue este formato es, sin duda, el dominante en Emilio Prados; aquel, en estado puro, está, en cambio, escasamente representado en su obra.

Cabe advertir, no obstante, que la originalidad de la poesía de estribillo del siglo xx no es tal, y que la división de esta clase de

${ }^{1}$ La edición utilizada es la de C. Blanco Aguinaga y A. Carreira: Emilio Prados (1999): Poesía completa. Madrid: Visor, 2 vols., seguramente la más completa.

${ }^{2}$ La crítica general observa acertadamente la predilección del poeta por las formas métricas tradicionales (como, por ejemplo, DEBıCKi 1968, LóPEz 1985 o LóPEz CAstro 1988), aunque no suele señalar el rasgo del desvío o quebrantamiento constante del modelo original. 
poesía en dos grupos diferenciados no es exacta en la medida en que la lírica popular que practica el estribillo, de tradición oral esencialmente, ha ido, a lo largo del tiempo, sufriendo cambios más o menos profundos y, en manos de los poetas más ávidos de experimentos líricos, incorporando elementos nuevos como supuestos agentes transgresores del canon. Podría decirse que lo que se ha producido es, simplemente, una evolución, sin que ello implique la aniquilación total y definitiva del patrón primitivo; la propia tradición ha ido dando forma a nuevos diseños estructurales del estribillo. Lo nuevo y lo viejo siempre han coexistido ${ }^{3}$.

Si el modelo convencional de la poesía de estribillo tradicional, inspirada en los remotos cantos litúrgicos y en las composiciones corales diseñadas para la recitación polifónica, utilizaba normalmente como estribillo un texto ajeno, por lo común anónimo (refrán, villancico, cantar, coplilla...), que, ubicado al comienzo de la composición a modo de frontispicio, tipográficamente diferenciado del resto como pieza de arquitectura exenta, marcaba la estructura métrica y temática de la composición, e, intercalado con regular periodicidad en el cuerpo del poema, servía como elemento organizador del mismo, seccionándolo en partes o estrofas que giraban en torno al mismo tema, y no pocas veces cerrándolo herméticamente, dicho modelo fue diversificándose ya desde sus más prístinos orígenes, tal como muestran numerosas canciones del medievo, introduciendo fórmulas originales, fruto indudable, en muchos casos, de la creatividad artística del poeta o el trovador, y así surgieron canciones de estribillo con variantes o, dicho de otro modo, con un estribillo que no se reproduce literalmente, cambiante en cada repetición; canciones con dos estribillos o enunciados iterativos alternantes; canciones decapitadas, despojadas de estribillo en la cabecera,

${ }^{3}$ Sobre la irregularidad de los modelos métricos regulares, es cita obligada el clásico estudio de Henríquez Ureña (1920). Puede verse también Frenk Alatorre (1990). Los manuales de métrica también recogen a veces variantes y contraejemplos de los metros y las formas estróficas tradicionales. En SÁNCHEz Romeralo (1969) y Spyropoulou Leclanche (1998), por ejemplo, se advierten así mismo variaciones del villancico arquetípico o del refrain, elementos poéticos estructurantes que, como es sabido, guardan una muy estrecha relación con el estribillo; de hecho, refrain y el villancico o coplilla de entrada se configuran en estribillo en numerosas composiciones. 
o que no se sellan con estribillo, a veces porque se añade, a modo de estrambote, un estrofilla de más; canciones en las que el estribillo no constituye la base temática ni rítmica, esto es, canciones con estribillo extratemático o semánticamente inmotivado, incluso convertido en mero adorno sonoro, en ripio, y canciones con estribillo extrarrítmico, con metro propio, independiente del que gobierna el resto del discurso; canciones con estribillo integrado en las estrofas, situado generalmente al comienzo o al final de las mismas; canciones con estribillo de periodicidad o frecuencia irregular, y canciones sin estructuración estrófica, a guisa de romances, que diseminan el estribillo de manera asistemática; canciones con un estribillo escasamente representativo (a veces, una palabra, una interjección...), y, al contrario, canciones de estribillo como estructura poética dominante o enfatizado en las que el discurso lírico queda extremadamente reducido al máximo, a la mínima expresión, a veces a un solo verso y a modo de historia secundaria; etc. ${ }^{4}$

Estas formas más o menos intensamente desviantes del modelo convencional representan la mayor parte de las creaciones líricas con estructura estribillística de Emilio Prados hasta el extremo a veces de ser un ejemplo palpable de la voluntad de ruptura con el modelo. Un rasgo sobresaliente del quehacer poético de Prados cuando adopta un patrón regular, sea métrico, sea estrófico, sea de una figura iterativa..., es la ruptura consciente de dicho patrón, que, con extrema frecuencia, tiene lugar en la parte final del poema. Prados no quiere que sus discursos poéticos queden rigurosamente ceñidos al estricto corsé de un patrón convencional; las rígidas normas del género han de ser contravenidas en alguna parte del cuerpo del poema, en el cierre generalmente ${ }^{5}$.

\footnotetext{
${ }^{4}$ De algunas de estas manifestaciones «irregulares», hay interesantes ilustraciones en García-Page (2003) y Luján Atienza (2010).

${ }^{5}$ Ya en García-PAge (2003) se hace referencia expresa a este rasgo de estilo de Emilio Prados, que coincide grosso modo con la observación de Del Castillo JiméNEZ (1985: 132-135). Sobre la ruptura del modelo en el cierre poemático, véase GARCía-PAGE (2005) y la bibliografía citada. A este fenómeno y a sus formas de expresión se hace alusión en diversos puntos de este trabajo.
} 


\section{Formas del estribillo en la obra lírica de Emilio Prados}

Como hemos indicado, en la obra lírica de Emilio Prados es casi imposible localizar una composición que adopte con todo rigor el modelo clásico del poema de estribillo, con texto anónimo exento, que abra y cierre el discurso sirviendo supuestamente de base temática y métrica al mismo, y que lo organice en partes o estrofas gracias a una repetición periódica, regular, en el interior de precisión matemática.

Hay, no obstante, algunas composiciones de estribillo en alto grado fieles al cantar estribillístico tradicional, como el fragmento poemático «Presagios», de Mosaico. Poema con espejismo (II, 699):

Cuando se abre el día soy cajero del Tedio, y en cuanto que obscurece tesorero de sueños.

En el taller del Tiempo entré como aprendiz de sastre.

Me salí porque supe que el Olvido se cubre de abanicos de aire.

Cuando se abre el día soy cajero del Tedio y en cuanto que obscurece tesorero de sueños.

Fui a regalarle al Sol un disfraz de cangrejo, por ver si así trocaba el camino del Tiempo, y me he vuelto, pues la alcancía de la tarde ya lo guardaba dentro.

Cuando se abre el día soy cajero del Tedio y en cuanto que obscurece tesorero de sueños.

Fui a pintar la noche color hoja de lata, porque el gallo del Tiempo se creyera en el alba, y me he vuelto, porque al salir de casa, cayó un pájaro muerto de una rama.

Cuando se abre el día soy cajero del Tedio y en cuanto que obscurece tesorero de sueños.

Aun así, no puede afirmarse que «Presagios» sea un texto totalmente obediente al canon de la canción de estribillo, entre otras razones, porque el estribillo no es un texto ajeno, porque no constituye fielmente la base métrica y porque la periodicidad de la repetición no es exacta al no ser idénticas las estrofas que conforman el cuerpo del texto. El estribillo es una copla o cuarteta asonantada de versos heptasílabos; el texto, aunque sigue 
este esquema básicamente, presenta algunos quebrados tetrasílabos y dos eneasílabos. La rima asonante de los versos pares del estribillo se copia, con no total exactitud, en la segunda estrofa y en la tercera, que refuerza la rima con otro esquema de asonancias en los versos impares (xbababab).

«Declaración de un culto», en Formación del paisaje, de $L a$ piedra escrita (II, 443), sigue un patrón similar, sólo que el estribillo es base métrica (endecasílabo).

«La escuela», de Seis estampas para un rompecabezas (II, 677), es otro ejemplo de canción de estribillo. Este, formado por dos pareados heterométricos (3-3/7-7) sin rima y gráficamente separados, se repite tres veces: en la cabeza y coda del texto, como indica el canon, y en el interior. La estructura rítmica del estribillo es alterada en los dos grupos estróficos divididos por el estribillo medial, dado que, por un lado, el segundo grupo incorpora dos versos pentasílabos y, por otro, sigue el esquema de rima asonante en los versos pares (salvo el sexto verso de la segunda estrofa, que queda suelto):

Tic tac.

Tic tac.

Sobre el catón del día el Tiempo deletrea...

Una esfera de cartón sobre la mesa bosteza y abiertos sobre el muro como ventanas ciegas nos ofrecen los mapas su lejanía muerta.

Tic tac.

Tic tac.

Sobre el catón del día el Tiempo deletrea...
El alma de una fragata, en urna de cristal presa, anclas de melancolía clava en aguas de madera;

$\mathrm{y}$ un atlas

medio dormido

sobre un pupitre

nos muestra

la mariposa del MAR

que entre sus hojas diseca...

Tic tac.

Tic tac.

Sobre el catón del día el Tiempo deletrea...

Otro poema de Emilio Prados próximo al modelo clásico es «Nocturno inmóvil», canción XIV de «I. Cantares, coplas y sentencias», de Jardín cerrado (nostalgias, sueños y presencias), Libro Segundo. El dormido en la yerba (I, 856), aunque, como en «Presagios», el estribillo (un tercetillo de verso hexasilábico 
con rima asonante $x a a$ ) no constituye la base métrica del texto (dos quintillas octosílabas simétricas divididas en dos partes con rima asonante $x x b x b$ ). El poema, de factura netamente paralelística, presenta una estructura fuertemente trabada y equilibrada, de medidas calculadas:

Prado de la noche.

Altas alamedas.

La luna y la yerba.

Sobre el cuerpo de mi sombra;

bien ajustado a mi sombra,

mi cuerpo duerme en el suelo.

Y ¿en dónde mi corazón?...

Buscando mis pensamientos.
Sobre la sombra, la noche, bien ajustada a su sombra, duerme en el cielo.

-Y ¿en dónde la luz del sol?

Alumbrando a los luceros.

Prado de la noche.

Altas alamedas.

La luna y la yerba.

Prado de la noche.

Altas alamedas.

La luna y la yerba.

¡Ya llegan los niños, madre!, de Poemas sueltos de la Guerra Civil (II, 852), es otra composición de estribillo representativa, si bien el estribillo -compuesto de cuatro versos heterométricos (3-5-4-6) con rima xxáá- no representa la base métrica del texto, constituido por seis estrofas de extensión distinta de versos hexasílabos con la misma rima asonantada en los pares [-í-a]. El estribillo (la primera estrofilla), con apariencia de texto ajeno al estar diferenciado tipográficamente con cursiva, presenta la particularidad de formar parte del conjunto estrófico también destacado con cursiva que funciona estructuralmente como señal de apertura y cierre del poema:

¡Ay, la madre,

los niños vienen:

llegan ya!

¿Quién los cogerá?

Vienen de la muerte, madre,

llorando suben del mar:

¿Quién los cogerá?

Desde el Norte blanco que en las nieves frías no cierra sus ojos

ni su llanto olvida.

Desde el Sur más blando

porque el sol más pisa

sus blandos sembrados

y sus aguas finas.

¡Ay, la madre,

los niños vienen:

llegan ya!

¿Quién los cogerá? 
De la seca tierra, hoy entre ruinas, que en anchas llanuras sostiene a Castilla. Desde Extremadura, lejana y cobriza, que en ricas dehesas muestra la codicia que, aún hoy, la amenaza mísera y altiva.
¡Ay, la madre, los niños vienen:
llegan ya!
¿Quién los cogerá?

Por los hondos valles, por las altas cimas, sobre duros páramos o por las orillas donde el mar refresca su ardor con sus brisas.

$$
\begin{aligned}
& \text { ¡Ay, la madre, } \\
& \text { los niños vienen: } \\
& \text { llegan ya! } \\
& \text { ¿Quién los cogerá? }
\end{aligned}
$$

Si a veces dichosos cantan su alegría, no siempre sus labios vieron la sonrisa, que hoy muerde en sus gozos la llama encendida que sobre la guerra deja sus cenizas, y a su primavera la muerte le envía las flores del llanto, frutos de desdicha.

$$
\begin{aligned}
& \text { ¡Ay, la madre, } \\
& \text { los niños vienen: } \\
& \text { llegan ya! } \\
& \text { ¿Quién los cogerá? }
\end{aligned}
$$

Invierno y verano dolor y alegría mis ojos han visto cruzando mi vida, mas nunca supieron por mis cortos días, de este dolor hondo que ya nunca olvidan. Alzando mis odios la voz de mis iras por las carreteras de España gemía y apretada al pecho mi sangre decía:

$$
\begin{aligned}
& \text { ¡Ay, la madre, } \\
& \text { los niños vienen: } \\
& \text { llegan ya! } \\
& \text { ¿Quién los cogerá? }
\end{aligned}
$$

Hoy ya mi tristeza cambio por mi dicha, que hoy los niños tienen fronteras más limpias y ya han olvidado su horror y fatiga; si un amor perdieron otro amor ya invita a que huya su llanto y vuelva su risa; pero yo no olvido ni mi sueño olvida las llagas abiertas que aún sus pies marchitan.
¡Ay, la madre, los niños vienen: llegan ya! ¿Quién los cogerá?

Vienen de la muerte madre, llorando suben del mar: ¿Quién los cogerá? 
Hay otras composiciones en las que el estribillo es parcialmente idéntico al cantarcillo o estrofa que sirve de apertura y cierre, o es parte de él, al repetir uno o varios versos del cantar, como ocurre en «La voz en el sueño», «Cantar triste» $\mathrm{y}$ «Jacinto en el alba», de Jardín cerrado (nostalgias, sueños y presencias), Libro Segundo. El dormido en la yerba (I, 867 y 844) y Libro Cuarto. La sangre abierta. Vuelta y perennidad en el jardín del cuerpo (I, 1033), y «Carchuna», de Cancionero menor para los combatientes (I, 541); en verdad, podría decirse que, en este último, el estribillo y el cantarcillo de apertura son la misma cosa, sólo que éste añade un verso repetido al estribillo medial; en este sentido, podría considerarse una forma de estribillo variable o con variantes (véase infra), que sigue el esquema de alternancia abrazada 1-2-2-1:

¡Mínima voz

el amor en lo eterno,

mínima voz!

-¿Mínima voz

la lluvia sobre el cielo?

-¿Mínima voz

la lluvia bajo el suelo?

-¿Mínima voz

el árbol sobre el tiempo?

-¿Mínima voz

lo eterno en el silencio?...

¡Mínima voz

el amor en lo eterno, mínima voz!

[2]

Yo no quería,

no quería haber nacido.

Me senté junto a la fuente

mirando la tarde nueva...
¡Bravo el andaluz!

¡Bravo el andaluz

que lo sepa ser!

Si lo sabe ser:

¡bravo el andaluz!

Granada, Sevilla, Málaga, Jaén... ¡Bravo el andaluz que lo sepa ser!

Tierras de Granada -bravo el andaluzla sierra serena contra el cielo azul.

Arisca es la sierra, verde el retamar. La flor del olivo floreciendo está.

¡Bravo el andaluz! que lo sepa ser!

Si lo sabe ser: ¡bravo el andaluz! 
El agua, brotaba lenta.

No quería haber nacido

Me fui bajo la alameda

A ocultarme en su tristeza.

El viento lloraba en ella.

No quería haber nacido.

Me recliné en una piedra, por ver la primera estrella...

¡Bella lágrima de estío!

No quería haber nacido

Me levanté de mi pena...

(Ya estaba en el sueño hundido.)

Yo no quería, no quería haber nacido.

\section{[3]}

Verde y pequeño, entre espadas, jacinto, tu flor abrasa.

Mis pies van buscando tierra.

Todo el jardín es estrella

de la noche, en que la hoguera

de tu flor tierna naufraga.

Que, aunque pequeña, entre espadas, jacinto, tu flor abrasa.

Yo estoy, como tú, cautivo de aroma. Tu aroma sigo... Y, como tú, en él me olvido, humilde marfil en llamas...

Que, aunque pequeño, entre espadas, jacinto, tu flor abrasa.

Diminuto, en ti me quedo temblando, en el blando fuego que, en invertidos luceros, de tu corola derramas.
Tierra de Granada, iprisionera estás!

¡Qué blanca es la espuma

a orillas del mar!

¡Qué blanca es la espuma, qué oscuro el silencio!

¡Qué serena el agua, qué blandos los remos!

Buenos andaluces, bravos asturianos, perdieron cadenas por alas cambiando.

Pierden sus cadenas y ganan sus alas... Contra el cielo azul la Sierra Nevada.

¡Bravo el andaluz! que lo sepa ser! Si lo sabe ser: ¡bravo el andaluz!

Bravo el andaluz, triste el asturiano que perdió sus tierras prisiones ganando.

Bravo el asturiano y el andaluz triste si guarda prisiones $\mathrm{y}$ en prisiones vive.

¡Málaga y Granada, Huelva con Sevilla, Córdoba con Cádiz, la blanca Algeciras!...

¡Ay tierra andaluza que hoy lloras cautiva! ¡Quién podrá curarte de tantas heridas! 
Que, aunque pequeña, entre espadas, jacinto, tu flor abrasa.

Como tú, al nacer, no olvidas

el suelo y hasta él inclinas

tu olor y nieve, flor cándida,

en él mi desmayo salvas.

Y aunque pequeña, entre espadas, jacinto, tu flor abrasa.

Y, en ti, contigo, hallo tierra.

Y de nuevo en la alameda

la estrella luce entreabierta

mientras el surtidor canta:

-Verde y pequeño, entre espadas, jacinto, tu flor abrasa

El tercer poema, «Jacinto en el alba», es uno de los pocos zéjeles de metro octosílabo al estilo más puro que compone Emilio Prados (es una cadena de zéjeles: aa bbba a a ccca...) ${ }^{6}$. Presenta la particularidad de que el elemento repetitivo que hace de estribillo se conforma como una versión distinta del pareado que sirve de apertura y cierre; de hecho, reproduce literalmente el segundo verso y recoge la parte final del primero: Verde y pequeño, entre espadas,/ jacinto, tu flor abrasa $\rightarrow$ Que, aunque pequeña, entre espadas,/ jacinto, tu flor abrasa.

Composiciones como éstas en que el estribillo es parcialmente idéntico al cantar de apertura y fin que envuelve el texto están a medio camino de aquellas que tienen dos coplas o dos elementos repetitivos distintos con función estructuradora, uno que se ubica en los extremos del discurso (comienzo y final) instituyéndose en señal de cierre circular y hermético, y otro, en el interior, que hace las veces del estribillo auténtico como elemento que organiza el texto en estrofas creando el ritmo alternante. «Vengo herido», de Cancionero menor para combatientes (I, 540) y «Canción», de Poemas sueltos de la Guerra Civil (I, 657), ilustran claramente esta situación:

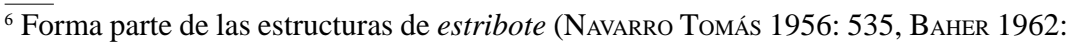
315, Domínguez CAPARRós 1993: 218). Sobre variaciones formales del zéjel, véase, p. ej., Morrás (1988). 
Vengo del agua del río

y vengo herido

al agua del mar:

¡al agua del mar!

Por las aguas de la muerte

bajo sus quebrados puentes.

Por los puentes de la luna, vengo de noche y a oscuras al agua del mar:

¡al agua del mar!

A las aguas de la oliva donde la guerra se olvida.

A las orillas del sol donde se olvida el dolor. al agua del mar:

¡al agua del mar!

A las aguas del mar iré y me curaré.

Sólo en el agua del mar me podré curar.

Vengo del agua del río $\mathrm{y}$ vengo herido.
La muerte pasa nadando entre naranjos y olivos: ¿a dónde la muerte irá? La muerte pasa cantando.

-Vengo de cruzar el Ebro:

Turbia es el agua.

-Vuelan las palomillas, los peces nadan.

-Vengo de cruzar el Ebro: el agua es negra.

-Negra y honda es mi herida y alta la estrella.

-Vengo de cruzar el Ebro:

roja es el agua.

-Suena el cañón lejano, silban las balas.

La muerte pasa nadando entre naranjos y olivos: ¿a dónde la muerte irá? La muerte pasa cantando.

En «Vengo herido», los elementos repetidos son, en los extremos, Vengo del agua del río/ y vengo herido y, en el interior, al agua del mar:/ ;al agua del mar!; y en «Canción», la redondilla octosílaba La muerte pasa nadando/ entre naranjos y olivos:/ ¿a dónde la muerte irá?/ La muerte pasa cantando, en los extremos, y, en el interior, Vengo de cruzar el Ebro, verso integrado al principio de cada estrofa.

«Temblor de estío», de Jardín cerrado (nostalgias, sueños y presencias), Libro Primero: Jardín perdido, I. Nostalgias y sueños (I, 798), sigue otro patrón. Los dos segmentos repetitivos, el estribillo de apertura y cierre (¿Qué me importa la alameda/ si no he de volver a ella?) -que es base temática y métrica al texto: un pareado octosílabo con rima asonantada (é-a)-, y el interno, que es el primer verso de cada estrofa -un dístico asonantado (-Al borde de la alameda)-, alternan de forma sistemática y regular; el estribillo que abre y cierra el poema, pues, no sólo tiene función envolvente: 
¿Qué me importa la alameda si no he de volver a ella?

-Al borde de la alameda hay una rosa entreabierta...

¿Qué me importa la alameda si no he de volver a ella?

-Al borde de la alameda hay un lucero que sueña...

¿Qué me importa la alameda si no he de volver a ella?

-Al borde de la alameda hay una sombra que espera...

¿Qué me importa la alameda si no he de volver a ella?

- Al borde de la alameda llora el agua entre las piedras... ¡Suspiran las hojas secas!

¿Qué me importa la alameda si no he de volver a ella?

Como el citado «Nocturno inmóvil» y otros poemas, se trata de una composición de configuración paralelística, que busca la simetría y la proporción. No obstante, E. Prados, como en un arrebato de rebeldía contra lo convencional y fijo, fuerza la ruptura del modelo: al final, se altera el esquema rítmico y sintáctico convirtiendo el dístico en un tríptico monorrimo y suprimiendo la estructura oracional del segundo verso, una oración impersonal con el esquema sintáctico: hay $+\mathrm{SN}[\mathrm{un}+\mathrm{N}+$ adyacente (adjetivo / oración de relativo)]. Como se dijo al principio y se han citado ejemplos, la contravención de la «norma» es un recurso estilístico frecuente en Prados.

Uno de los ejemplos más representativos de esta suerte de recurso poético es «Cancioncilla de la desvelada», de Cancionero menor para combatientes (I, 538): los dos estribillos son exentos y simulan ser textos ajenos por su resalte con cursiva; cada uno se repite tres veces, aunque el esquema de alternancia es 1-1-2-2-2-1: 
Estando dormida sentí gran dolor. Pregunté a mi sueño, respondió mi amor:

Levántate de prisa que te espero: ¿cómo descansas cuando yo me muero?

Me volví a dormir, volví a despertar, mis ojos con lágrimas, mi alma con pesar.

Levántate de prisa que te espero: ¿cómo descansas cuando yo me muero?

Antes de que el alba comenzara a entrar, salté de mi lecho, dejé de llorar.

Espera, aguarda que de prisa llega: ¿cómo descansaré con este fuego?
Con la luz del sueño mi aguja perdí, con la luz del alba de nuevo la vi.

Espera, aguarda que de prisa llega: ¿cómo descansaré con este fuego?

Mi aguja en el día de nuevo encontré. Cuando entre la noche a mi amor diré:

Espera, aguarda que de prisa llega: ¿cómo descansaré con este fuego?

Y otra vez mi sueño ¡qué alegre será! La voz de mi amante ya no me dirá:

Levántate de prisa que te espero: ¿cómo descansas cuando yo me muero?

Otro procedimiento de alternancia que utiliza Prados lo constituye el estribillo que podríamos llamar variable, un estribillo codificado en dos o más versiones. Estas dos versiones han de ser muy similares para que pueda interpretarse que hay un único estribillo. La variación puede consistir en un cambio léxico, gramatical..., o, simplemente, gráfico o tipográfico. «Nocturno fiel», de Poemas sueltos anteriores a 1930 (I, 407), y el poema 3 de Llanto de octubre (I, 449), ilustran magistralmente este recurso. En el primer caso, el estribillo está formado por dos versos paralelísticos que repiten el mismo enunciado, sólo diferenciados al final por las palabras cielo y suelo; el carácter alternante del estribillo se consigue invirtiendo el orden de aparición de dichas palabras. En el segundo caso, la situación es más compleja: por un lado, el segundo verso del dístico-estribillo variable («Los perros 
aullaban» / «en la madrugada») sigue un método de alternancia distinta, envolvente o abrazada, según el esquema 1-2-2-1; por otro lado, la variación que presenta el primer verso, mediante el trueque de los lexemas golpes y sombras, sigue el esquema 1-12-2:

Luna en el cielo.

Luna en el suelo.

El mar entra por la noche y la noche por el sueño...

Luna en el suelo.

Luna en el cielo.

Dando la mano a su sombra cruza el hombre por el tiempo...

Luna en el cielo.

Luna en el suelo.

Canta el olivar dormido en los brazos del silencio...

Luna en el suelo.

Luna en el cielo.

Cierra la muerte sus alas sobre la espalda del viento.

Luna en el cielo.

Luna en el suelo.
Sonaron tres golpes junto a mi ventana. Sonaron tres golpes allá en la montaña.

Tan, tan, tan. Tres golpes. Los perros aullaban.

El viento gemía, sollozaba el agua. sobre el cielo negro la luna se alzaba.

Tan, tan, tan. Tres golpes en la madrugada.

Cruzaron tres sombras bajo mi ventana. Tres sombras más negras que sus negras almas.

Tan, tan, tan. Tres sombras en la madrugada.

Ni el viento gemía, ni lloraba el agua.

Se escondió la luna tras las nubes altas.

Tan, tan, tan. Tres sombras. Los perros aullaban.

Hoy sólo el silencio rueda por mi casa.

«Llanuras de sol», de Jardín cerrado (nostalgias, sueños y presencias), Libro Primero. Jardín perdido, I. Nostalgias y sueños (I, 772), presenta el estribillo alternante, con esquema 1-2$1-2$, con variación exclusivamente gráfica: las dos versiones difieren en la puntuación del final del verso. Se trata de uno de 
los poemas que, por la forma, más fielmente sigue el modelo convencional de estribillo: un texto exento que abre y cierra el discurso y lo estructura en estrofas regulares, simétricas, repitiéndose en el interior con una periodicidad regular:

Campo, campo y más campo...

-¿YY el olivar?

(Mi corazón soñando.)

Campo, campo y más campo.

(¿Qué me persigue, Dios, qué me persigue?...)
Campo, campo y más campo...

Y ¿dónde el mar?

(Mi corazón llorando.)

Campo, campo y más campo.

Hay otra suerte de estribillo variable que consiste en presentar una versión lingüística distinta en cada repetición. He aquí dos ejemplos ilustrativos: el poema XXI de Penumbras, I (II, 871) y «Bajo el ciprés», de Jardín cerrado (nostalgias, sueños y presencias), Libro Primero. Jardín perdido, I. Nostalgias y sueños (I, 804):

¿Quién ha desnudado al cielo?...

(Vuela -asciende la lluvia-...

Desde invertidos suelos

la yerba cae...

Las hojas se derraman...)

¿Quién ha desnudado al agua?...

(Mi cuerpo es un reflejo:

ángulo en doble imagen

de un silencio...)

¿Quién ha desnudado al viento?...

(Ese lucero tan hondo, aquel lucero tan alto...)

¿Quién ha desnudado al espacio?
En el huerto me he dormido.

Árbol sin nacer: ¿qué olvido futuro, será tu sombra?

Árbol de ayer: ¿en qué sueño

tu olvido su mano ahonda?...

En el huerto he despertado.

Morado alhelí: ¿qué fuego quema tu aroma lejano? Jazmín -temblor de la noche-: ¿qué fuente te está llamando?

En el huerto estoy sentado.

Cuerpo triste: ¿en qué rocío tu pena se está mojando?...

(Huele el sándalo florido y mueve el viento el mastranzo. Flota la luna en la acequia...)

En el huerto estoy llorando. 
Son otros ejemplos «El tiempo en la sangre» y la canción I de Canciones del farero, citados más abajo, «Caminante del sueño», de "Últimas nostalgias del jardín perdido», de Jardín cerrado (nostalgias, sueños y presencias), Libro primero. Jardín perdido, I. Nostalgias y sueños (I, 797) o «Misterio», de Vuelta (I, 196).

Cuando los cambios son consistentes, no es fácil decidir su rango de estribillo. Son otros factores, de orden rítmico, como el esquema acentual o sintáctico, y el carácter cíclico de la repetición, los que permiten aventurar su análisis como estribillo. Es lo que ocurre en el poema «La voz en el jardín», de Jardín cerrado (nostalgias, sueños y presencias), Libro Tercero. Umbrales de sombra. II. Otro amor (I, 964):

Corazón, hoy te he visto salido de mi cuerpo, andar desnudo por la calle.

¡Qué sonrisa era el cielo!

Me acerqué para hablarte y sólo te miré...

También tú, te acercaste; pero seguiste luego, corazón, sin hablarme.

¡Qué temblor en el aire!

-Si él me tocara, sólo, tan sólo con un dedo sobre la piel del hombro.

(Pensábamos los dos...)

¡Qué temor en la sangre!

-Vencerá ese silencio, la piel de nuestro sueño, amor...

amor...

(Cantaba el Tiempo.)

Y seguimos andando, sin voz por el misterio...

¡Qué suspiro en la tarde! 
Junto a estas canciones, algunos poemas con cierre circular o envolvente carecen de estribillo medial, es decir, las coplillas que abren y cierran el poema no se repiten en el interior. Es un artificio poético recurrente en Prados, como ilustran las breves poesías «Reflejo», de Tiempo. Veinte poemas en verso (I, 148), e «Insomnio», en «IV. Primeras nostalgias del jardín perdido», de Jardín cerrado (nostalgias, sueños y presencias), Libro Primero: Jardín perdido, I. Nostalgias y sueños (I, 774); su análisis como formas de estribillo resulta controvertido:

Abrí la caja de los peces

y se cuajó el cielo

de luceros verdes.

-Dame tu doble aparejo, con su compás de caña y con su doble anzuelo-.

Abrí la caja de los peces y se cuajó el cielo de luceros verdes.
¿Tordos en el olivar?...

-No, tordos, no.

(¿Qué tengo, que no duermo?

Soñar no quiero...

Pero, ¿qué tengo?

-Tordos en el olivar, no.

-No, tordos, no.

Adviértase, una vez más, que la repetición no es exacta en «Insomnio»: en el primer verso de la coplilla existe una ligera variación gráfica y léxica.

Son también abundantes los poemas cuyo estribillo encabeza la composición pero no la cierra y, por lo tanto, el estribillo no funciona como señal de límite del discurso. Uno de estos poemas es «Calmas», de Vuelta (I, 214): el estribillo, exento, está representado por una estrofa constituida por un único verso heptasilábico que se repite tres veces, metro que adopta también el cuerpo del texto, a excepción del segundo verso de la primera estrofa, que es un quebrado pentasílabo; las partes en que queda organizado el cuerpo del texto no guardan homogeneidad estrófica entre sí, lo que, junto al hecho de estar éstas articuladas en conjuntos desiguales de versos (algunos son monoversales y se sitúan próximos al verso-estribillo), crea un efecto de difumino del carácter cíclico de la repetición del estribillo; éste aparece camuflado en el interior: 
Palma, cristal y piedra.

El nácar del perfil puro del gesto, enérgico en el agua.

Extractada la brújula

sostiene el equilibrio

vertical sobre el viento...

El imán se detiene.

Palma, cristal y piedra.

Por el muelle, despacio, la memoria indolente se apoya en la baranda de un crepúsculo hábil.

El sueño se devana, y se humedece el tiempo al entregar su cinta...

Húndese el movimiento.

Palma, cristal y piedra.

Por el muelle del día pierde la memoria.

La mirada se vierte líquida en el olvido.

El alma se separa.

A veces, el estribillo no cierra el poema porque el autor añade al final un verso o una estrofa a modo de estrambote o remate arquitectónico, que, si no ajenos, podrían antojarse superfluos, como ocurre en la canción XVII de Circuncisión del sueño, II. En la gracia del viento (II, 319) y «Germinal» (XX), de El dormido en la yerba (I, 865):

«Hacia el monte!»

«HHacia el monte!»

(¡Mañana inquieta!...)

«iHacia el monte!»

«iHacia el monte!»

(¡Cruje la siesta!...)

«Hacia el monte!» «Hacia el monte!»

(¡Noche entreabierta!...)

«iHacia el monte!» «iHacia el monte!»

(-Yo aquí me quedo, arroyo claro, fuente serena, que hacia el monte se vaya quien no nos vea...)
Cerraron todas las puertas. Quedó desnuda la noche, cautiva sobre la yerba.

(-Yo estaba allí:

¿no me viste?...

Yo estaba allí

Bajo el agua:

¿no me viste?)

Piel de anillo, la muralla sueña su nieve y resiste al verde ardor de las ramas...

(-Yo estaba allí:

¿no me viste?...

Yo estaba allí

Bajo el agua:

¿no me viste?)

¡Jardín cerrado, mi alma! 
Ciertos cambios externos, como la forma estrófica y la tipografía refuerzan la impronta de elemento ajeno. Así, en el primer texto, la estructura pentaversal del último grupo estrófico, el que sea la letra de una canción popular («Arroyo claro,/ fuente serena») y su encuadre en un paréntesis subrayan el carácter de elemento añadido. Sin embargo, como contraprestación, el añadido produce el efecto de cierre total al bloquear la posibilidad de recurrencia del estribillo.

Asimismo, en «La rosa en pena», de Mínima muerte. II Mínima muerte. Trinidad de la rosa (I, 741), un breve relato parentético añadido deliberadamente por el autor a modo de colofón, temáticamente ajeno al texto, niega al dístico («Era el llanto de la cal./ Era el frío») su función de señal de límite, al tiempo que impide el cerramiento circular del discurso, cuya simetría queda, además, rota: el discurso está concebido como un todo estructurado en partes semejantes que el estribillo ha seccionado. La estrofa previa a la última ocurrencia del estribillo, aunque más breve y formalmente distinta, constituye, en realidad, un resumen del discurso, lo que refuerza la impresión de cierre temático: se produce la recolección de las palabras clave (tres parónimos rimados: flor, olor, dolor) que han sido diseminadas en los tres grupos estróficos anteriores (la tercera aparece con un parasinónimo: «vamos a la flor / al olor / a la rosa del llanto»):

Era el llanto de la cal.

Era el frío...

Venid,

vamos a la flor

¡que aún no ha nacido!

-Venid,

vamos a cortarla

antes que nazca.

-Antes que pueda morir por nacer.

Antes de que llegue a ser, antes que pueda vivir, vamos a coger la flor: ¡vamos a cortarla antes que nazca!
Era el llanto de la flor.

Era el frío...

-Venid, vamos al olor de la flor que ha sido.

-Venid, venid.

Vamos, vamos

hacia la rosa del llanto: ¡que se ha ido!

-¿Antes de nacer murió?

-iY alguien la vio!

Alguien a la rosa vio que se ha perdido.

-Venid, vamos a su olor: que ya se ha ido.

¡Vamos a la flor! 
Era el llanto de la flor.

Era el frío...

-Venid, vamos a la flor, vamos a su olor, vamos al dolor: ¡que ya ha nacido!
Era el llanto de la flor.

Era el frío...

(Un paso daba la Muerte y otro borraba el Olvido.)

Son numerosos los poemas en que Emilio Prados practica este artilugio artístico del estrambote, como la canción VIII («Cuando era primavera»), de Penumbras I, inscrita en Otros poemas III (II, 598), la canción I de Canciones del farero (I, 181) o la canción VII de Penumbras II (II, 17); se exponen a continuación estos dos últimos:

Ya pisa en el horizonte la caracola del día...

(De ángeles se cubre el agua, que están tejiendo guirnaldas. Hoy, ¿qué fragata vendrá?

-Fragata de viento y mar.)

Ya va por el horizonte la caracola del día...

(Un barco sale del puerto, pintando el cielo de negro, Los ángeles se han tiznado y hacia la gloria han volado.)

Ya se va del horizonte la caracola del día...

(Un pez brota de las olas, rojo como una amapola. Trae en la boca una flor que parece un corazón.)

Ya traspuso el horizonte la caracola del día...

(Tres ángeles enlutados sobre la mar se han sentado.)
-¡Ábreme!...

llamo en mí mismo.)

La abro a mí mismo. ¡Al aire sueño que vivo!

-¡Ábreme!...

(Con mi sueño

llamo en mí mismo.)

La abro a mí mismo. ¡Al aire mi sueño vivo!

-¡Ábreme!...

(Con el aire

llamo en mí mismo.)

La abro al aire ¡En el aire vuelo conmigo!

(Vuelo y no vuelo: por dos alas herido sangro sin cuerpo.) 
Abundan también los poemas en que el estribillo, al contrario de lo que ocurría en los textos anteriores, no abre pero sí cierra el discurso; se consigue así una ruptura mayor con el modelo convencional puesto que, al no situarse en la cabecera, no puede asumir la función de organizador métrico y temático de la composición. Junto a otros ya citados, los poemas «Bajo la alameda» (IV) y «Desvelo» (XVIII), de Jardín cerrado (nostalgias, sueños y presencias), de Libro Primero. Jardín perdido, I. Nostalgias y sueños (I, 778) y Libro Segundo. El dormido en la yerba (I, 862), respectivamente, ilustran claramente esta situación, si bien el estribillo del primero -un pareado (entre paréntesis) - tiene el mismo esquema rítmico cuantitativo que las estrofas -tercerillas-: todos los versos, a excepción del segundo de la última estrofa, son hexasílabos:

La noche cerrada.

-¿Dónde está el jazmín?

Dormido en el agua.

(¡Qué alto el ciprés!

¡Qué alto el lucero!)

La fuente, callada.

-¿Dónde está la noche?

Dormida en el agua.

(¡Qué alto el ciprés!

¡Qué alto el lucero!)

Si te viera, amor,

si te viera...

-Ay, ¿dónde está el agua?

(¡Qué alto el lucero!

¡Qué alto el ciprés!)
¿Y si las alamedas

me llevaran al sueño?...

(Y en el sueño, dormido espero.)

¡Ay, si me llevarán...

¡Ay, si me llevan...

(Y un silencio

me sale del corazón;

me recorre todo el cuerpo.)

¡Ay, si me llevarán...

¡Ay, si me llevan...

Algo no muy distinto puede decirse del poema «El escucha», de Cancionero menor para los combatientes (I, 531): el estribillo, destacado tipográficamente con cursiva, presenta el mismo esquema rítmico de cantidad (combinación de heptasílabos y pentasílabos) y, parcialmente, de timbres (rima aguda / rima asonante en los pares, cambiante en cada estrofa) que las estrofas (seguidillas con estructura 7x-5a-7x-5a): 
Sobre el agua, una sombra vuela en silencio.

Está sin puente el río, sin luna el cielo.

La rama del invierno larga y sin flor.

Naranjales quemados.

Tierra sin sol.

Resbalando en la noche se escapa el día.

El soldado, a la estrella su muerte fía.

La rama del invierno larga y sin flor.

Naranjales quemados. Tierra sin sol.
Entre estrella y estrella vuela la sombra.

Los ojos del soldado cuentan las horas.

La rama del invierno larga y sin flor. Naranjales quemados. Tierra sin sol.

Mientras cuenta, la sombra se va acercando...

(Baja está la llanura y el monte es alto.)

Naranjales quemados.

Tierra sin sol.

La rama del invierno

larga y sin flor.

Ahora bien, la variante introducida en el último estribillo (se invierte el orden de los dísticos: La rama del invierno / larga y sin flor. / Naranjales quemados. / Tierra sin sol $\rightarrow$ Naranjales quemados. / Tierra sin sol. / La rama del invierno / larga y sin flor) produce el efecto de cierre final o absoluto al frustrar las expectativas de repetición cíclica del estribillo. Como ya se ha visto, la transgresión del esquema fijo sobre todo al final de la composición es una estrategia que Emilio Prados emplea de forma recurrente.

También son numerosos los poemas en los que el estribillo ni abre ni cierra el discurso y se sitúa únicamente en el interior, distribuyendo las estrofas, como ilustran «Tres canciones (I)» y «Plazuela» (XII), de Libro Segundo. El dormido en la yerba (I, 881 y 853). Se alejan, así, aún más del modelo convencional en que el estribillo, en cabeza, suele marcar el tema y el metro del desarrollo del discurso lírico. En el primero, el estribillo es una tercerilla octosilábica de rima aguda en los versos impares que se configura como la tercera y quinta estrofas; en el segundo, el estribillo es un verso exento de metro octosilábico como el resto del poema: 
Puente de mi soledad: con las aguas de mi muerte tus ojos se calmarán.

Tengo mi cuerpo tan lleno de lo que falta a mi vida, que hasta la muerte, vencida, busca por él su consuelo.

Por eso, para morir, tendré que echarme hacia dentro las anclas de mi vivir.

Y llevo un mundo a mi lado igual que un traje vacío y otro mundo en mí guardado que es por el mundo que vivo.

Por eso, para vivir, tendré que echarme hacia dentro las anclas de mi morir.

Puente de mi soledad: por los ojos de mi muerte tus aguas van hacia el mar, al mar del que no se vuelve.
En medio del corazón hay una fuente escondida.

(¡Qué aroma tiene la noche!)

Hay una fuente sin vida en medio del corazón.

(¡Qué aroma tiene la noche!)

¡Ay, corazón!: ¿quién te olvida?... (¡Qué aroma tiene la noche!)

En medio del corazón hay una estrella caída.

Latiendo estaba el silencio, cuando se acercó la luna.

Hay una hoja en el viento... (¡Qué aroma tiene la noche!)

Hay una hoja en el suelo. (¡Qué aroma tiene la noche!)

Hay una estrella marchita. (¡Qué aroma tiene la noche!)

¡Ay, corazón!: ¿quién te olvida?...

Otro aspecto del estribillo tiene que ver con su extensión y la relevancia que se le quiera otorgar. Hay, en Prados, dos fórmulas aparentemente contrarias: el estribillo corto o breve, reducido a la mínima expresión: un verso (con frecuencia encerrado entre paréntesis), acaso una palabra..., y el estribillo extenso o dominante que destaca sobre un texto corto, formado por estrofas simples, a veces extraordinariamente reducido.

La primera situación está representada por los poemas «El tiempo en la sangre», «La voz del jardín» y «Soledad», de Jardín cerrado (nostalgias, sueños y presencias), incluidos en Libro Primero. Jardín perdido, I. Nostalgias y sueños, Tercero. Umbrales de sombra. Meditaciones, coplas, insomnios y presentimientos, al margen de un jardín, II. Otro amor y Segundo. El dormido en la yerba (I, 813, 949, 934), respectivamente: 
Ay, la sombra que eras tú ayer cuando yo te vi tras de la tarde perderte: ¿a dónde se te fue, luz?

(Corazón, cállate.)

¿A dónde te fuiste ayer que, bajo la luz te entraste sin sombra, toda tu sombra dándole al cielo su sangre?

(Corazón, cállate.)

¿En dónde estás, arboleda que al jardín le diste templo de altura, en la soledad obscura, de tu silencio?

(Corazón, cállate.)

Di, vida: ¿por dónde vuelas? ¿Dónde estás? ¿Dónde has perdido los suelos de tu defensa?

(Corazón, ábrete.)

Moja una rama en la fuente las hojas de su desmayo. Cruza la noche... Un lucero, bebe en la fuente su llanto.
Sobre el agua de la noche, flota la flor de una estrella...

(Mi pecho contra tu pecho: ¡qué obscura pared de sangre!)

$-\mathrm{iAy}$ !

Bajo el agua de la noche, se hunde la flor de una estrella.

(Mi sueño contra tu sueño ¡qué cielo en la luz nos abre!)

- iAy!

¿Que un beso quedó perdido?... -Lo que fue beso es suspiro.

$-\mathrm{iAy}$ !

[3]

Latiendo estaba el silencio, cuando se acercó la luna por el cielo....

(La sombra se estaba abriendo.)

Exánime está el silencio. $\mathrm{Y}$ ¿dónde se fue la luna por el cielo?...

¿En dónde estás, corazón?...

-Corazón, te estoy velando...

(Corazón, párate.)

(La sombra se estaba abriendo.) -¿Quién va?...

(Sobre el horizonte se está desangrando el agua a borbotones.) 
La segunda situación (estribillo dominante) puede ejemplificarse con el siguiente texto de Mínima muerte. Trinidad de la rosa (I, 730). Se trata de un poema paralelístico, de estructura simétrica perfecta con estribillo clásico o convencional: sin variaciones formales, que abre y cierra la composición y de periodicidad matemática en la repetición, detrás de cada estrofa monoversal, según el esquema alternante ExExEx...:

Mirando el agua
la rosa
y junto a la rosa
yo,
mirando el agua.
(La luz era el alba.)
Mirando el agua
la rosa
y junto a la rosa
yo,
mirando el agua.
(El sol era un ascua.)
Mirando el agua
la rosa
y junto a la rosa
yo,
mirando el agua.
(La tarde empezaba.)
Mirando el agua
la rosa
y junto a la rosa

yo,

mirando el agua.

(¡Qué noche tan alta!)

Mirando el agua

la rosa

y junto a la rosa

yo,

mirando el agua.

(¡Qué estrellas tan bajas!)
Mirando el agua
la rosa
y junto a la rosa
yo,
mirando el agua.
(¡Qué azul vuelve el alba!)
Mirando el agua
la rosa
y junto a la rosa
yo,
mirando el agua.

Con este esquema de alternancia, se consigue realzar la función del estribillo y subrayar el carácter de composición estribillística. Cuando el índice de recurrencia del segmento repetitivo es bajo o su ubicación no es regular, al no seguir un orden prefijado o al ser desiguales las estrofas, se atenúa su impronta de estribillo; incluso su análisis como estribillo es arriesgado. Compárense, a modo de ejemplo, los textos «La sangre encendida» y «Todo se ha perdido», ambos de Jardín cerrado (nostalgias, sueños y presencias), Libro Cuarto. La sangre abierta. 
Vuelta y perennidad en el jardín del cuerpo (I, 1035) y Primero. Jardín perdido, I. Nostalgias y sueños (I, 801). Aunque tienen en común el que el estribillo abre y cierra el poema y no presenta variantes, sólo el primero adopta el esquema alterante ExExEx..., con la circunstancia favorable, además, de que las estrofas son métricamente equivalentes (cuartetas de heptasílabos y pentasílabos), aunque la disposición tipográfica parezca quebrar la simetría:

Que me cela

y me ronda la luna.

¡Que me cela!

¡Ay,! ¡mi cuerpo! ¡qué espinas

me lo han robado!

(La noche y el rocío

lo andan buscando.)

Que me cela

y me ronda la luna.

¡Que me cela!

-¿El ciprés?...

¡No!

¿Esa sombra?...

(Quieto el frío

en los labios del viento,

cuaja en suspiro.)

Que me cela

y me ronda la luna.

¡Que me cela!

$-¿$ ¿Se han quejado los juncos?...

$-\mathrm{iNo}$ !

(En la cañada,

un lucero sin brillo

se hunde en el agua.)

Que me cela

y me ronda la luna.

¡Que me cela!

¿Acaso entre los árboles

(qué obscuro llanto)

no es el eco de un beso

que está manando?..
¡Ay, sombra, sombra, búscame por el fuego!

Me acerco a la mariposa:

¡está al fondo del estanque!

Me acerco al árbol más bello:

¡está al fondo del estanque!

Me acerco al niño que juega:

¡está al fondo del estanque!

Me acerco al alma, en silencio:

¡está al fondo del estanque!

¡Ay, sombra, sombra,

búscame por el fuego!

Vi la tarde abierta, quise entrar en ella...

¡Buscaba el alivio de otras tardes, muertas!

Un jazmín cantaba su aroma de estrella...

-iAy, sombra, sombra, búscame por el fuego!

¡Ay, jazmín!...

su flor está en tierra.

Me acerco:

Un árbol soñaba

toda una alameda.

Me acerco...

sobre el suelo, secas.
Sus ramas, 
Que me cela

y me ronda la luna.

¡Que me cela!

Sangre, sangre, ¡tan fría!

qué fuego pones

bajo las alamedas

donde te escondes...

Que me cela

y me ronda la luna.

¡Que me cela!

¡Sombra, sombra, ya!

yerba sin rocío:

Déjame,

más lejos que mi cuerpo

llega el olvido.

Que me cela

y me ronda la luna.

¡Que me cela!
Era el ascua el pájaro

¡luz de primavera!

Me acerco...

ceniza en la yerba.

Sus alas,

¡La yerba, la yerba!

¡Oh final ternura!

(¡Me arrodillo en ella!...)

¡Mis labios!...

(Mis besos, se quiebran

sin eco, en la arena...)

¡Ay, sombra, sombra, búscame por el fuego!

Aún me queda una esperanza:

¿no seré yo el que esté muerto?

¡Ay, sombra, sombra, búscame por el fuego!

«Cruz del cuerpo», «Jazmín de la noche», «Ojos de la muerte», «Jacinto en el alba», "Cruz de la sombra», todos de Jardín cerrado (nostalgias, sueños y presencias), Libro Cuarto. La sangre abierta. Vuelta y perennidad en el jardín del cuerpo (I, 1027, 1029, 1031, 1033), salvo el último, de Libro Tercero. Umbrales de sombra (I, 900), y el citado «Declaración de un culto», están entre los poemas más próximos a la canción de estribillo tradicional de esquema alternante. Pero son también muchos los poemas en los que la periodicidad con que se repite el estribillo es irregular, como en "Sin saber por qué» y la primera canción de «Meditación Primera», de Mínima muerte (I, 697, 702).

También incide en la interpretación como estribillo de un elemento iterativo el número de veces que éste aparezca: resulta más controvertido tratarlo como estribillo si su presencia en la composición es mínima, esto es, si aparece sólo dos veces, máxime si es un poema extenso, como el «Cantar del dormido en la yerba», de Jardín cerrado (nostalgias, sueños y presencias), Libro Segundo. El dormido en la yerba (I, 835): 
La muerte está conmigo; mas la muerte es jardín cerrado, espacio, coto, silencio amurallado por la piel de mi cuerpo, donde, inmóvil -almendra viva, virgen-, mi luz contempla y da la imagen redimida, del fuego.

Si he de morir, ya es muerte: la estrella, la avenida, el silencio, la noche, el agua y el amor.

Lo dice así, la fuente y el suspiro.

\section{También}

mi sangre cuando besa.

Si he de morir: mis labios, vencidos de misterio, ya nada buscan: cantan, pues no ha de ser mi olvido la tierra ni el silencio...

Y el jazmín, no pregunta desmayado en la sombra: -¿¿A dónde irá el lucero que mi nieve ha perdido?...

Si ha de morir: su aroma es muerte; su flor muerte, como la tierra húmeda del cerrado jardín de mi alma, es carne de la muerte, también: ¡Luz! ¡Fúlgida memoria! ¡Eje de un universo nuevo, que va a nacer su niebla, al fin, de olvidos!

Lo dice así, la fuente y el suspiro.

mi sambre cuando besa.

En idéntica situación está «Dormido en la yerba» (I, 858), del mismo poemario.

Hay otros aspectos, ya mencionados, que afectan a la categorización como estribillo de un segmento iterativo, como su aislamiento tipográfico o su naturaleza exenta: la impronta de estribillo queda, siquiera visualmente, atenuada o difuminada si aparece embutido o incrustado en una estrofa, aunque suele compensar esta deficiencia ubicándose en un lugar métricamente relevante, como el principio o el final de la estrofa. "Sueño», de Cuerpo perseguido. 5 de abril (I, 366), y «Canción», de «Poemas sueltos de la guerra civil» (I, 660), ilustran magistralmente este artificio (adviértase la ruptura de la simetría total en la última estrofa de este segundo texto): 
Te llamé. Me llamaste.

Brotamos como ríos.

Alzáronse en el cielo

los nombres confundidos.

Te llamé. Me llamaste.

Brotamos como ríos.

Nuestros cuerpos, quedaron

frente a frente, vacíos.

Te llamé. Me llamaste.

Brotamos como ríos.

Entre nuestros dos cuerpos, ¡qué inolvidable abismo!
No es lo que está roto, no, el agua que el vaso tiene; lo que está roto es el vaso y el agua al suelo se vierte.

No es lo que está roto, no, lo que sujeta al día;

lo que está roto es su tiempo $\mathrm{y}$ en la sombra se desliza.

No es lo que está roto, no, la sangre que te levanta; lo que está roto es tu cuerpo y en el sueño te derramas.

No es lo que está roto, no, la caja del pensamiento; lo que está roto es la idea que la lleva a lo soberbio.

No es lo que está roto, Dios ni el campo que Él ha creado; lo que está roto es el hombre que no ve a Dios en su campo.

En «Cuando era primavera», de Penumbras, $I$, en «Otros poemas, III» (II, 598), el primero y último versos (Cuando era primavera en España / Cuando era primavera) son los elementos repetitivos, si bien este esquema es roto en la estrofilla final.

En la canción V de Penumbras, I, de Otros poemas, III (II, 863), y «Bajo la alameda» de Jardín cerrado (nostalgias, sueños y presencias), Libro Primero. Jardín perdido (I, 803), también se efectúa la violación del modelo de simetría: el supuesto estribillo (primer verso y último, respectivamente, en sendos poemas), que se repite integrado en las tres tercerillas, queda solo, exento, al final del poema formando estrofa. Este aislamiento funciona como señal de límite o cerramiento absoluto, acentuado, en el primer caso, por el cambio parcial de la estructura sintáctica y léxica del estribillo, y, en el segundo, por su sustitución por otro verso en el último tercetillo: 
-Alto pinar, no me enredes... (¿En qué cielo vegetal se va alejando esa nube?)

-Alto pinar, no me enredes... (Ahogándose en el descanso me estoy durmiendo en la tierra)

-Alto pinar, no me enredes:

deja que al viento, en tus ramas, húmedo de luz me entregue.

-Alto pinar, no despiertes.
¿Quién cruzó la noche?

-iYo!

Pues cállatelo.

¿Quién rompió la noche?

-iYo!

Pues cállatelo.

-¡No, que el jazmín

ya está naciendo;

que ya se está abriendo!

Pues cállatelo.

No obstante, el poeta puede contrarrestar este difumino del estribillo realzándolo mediante cualesquiera otras estrategias artísticas, como, por ejemplo, aumentando su presencia. En «Cantar del atardecer», de Jardín cerrado (nostalgias, sueños y presencias), Libro Primero. Jardín perdido. II. Las alamedas (I, 823), el estribillo se repite machaconamente al comienzo de cada estrofa; y en «Canciones (III)», en Pacto interior, de Circuncisión del sueño (II, 303), el ritmo repetitivo cobra un cariz letánico:

¡Altas alamedas!

(Y el viento con ellas.)

¡Altas alamedas!

(¿Y las hojas secas?)

¡Altas alamedas!

(La tarde está abierta)

¡Altas alamedas!

(Y la luna llega.)

¡Altas alamedas!

(La noche se acerca.)

¡Altas alamedas!

(Y el otoño dice:

¡Altas alamedas!)

¡Altas alamedas!

(Y la luna sueña.)

¡Altas alamedas!

(El lucero espera.)
Me miré en la piedra

-ique sus ojos me vean!-, me hundí por ella.

-iQue sus ojos me vean!-.

La levanté a mirarme

-ique sus ojos me vean!-,

me hundí en el aire.

-iQue sus ojos me vean!

Tres ramas se movían

-ique sus ojos me vean!-,

En mí nacidas...

-ique sus ojos me vean!-,

Cuando salí del agua

-ique sus ojos me vean!-,

no hallé mis ramas.

-iQue sus ojos me vean!

Cayó el viento en la poza -ique sus ojos me vean!-, su cuerpo es sombra.

-iQue sus ojos me vean!-...

Me desnudé del viento 
¡Altas alamedas!

(El agua, ¡tan quieta!)

¡Altas alamedas!

(La noche se cierra.)

¡Altas alamedas!

(¿Y esa estrella muerta?)

¡Altas alamedas!

(El eco repite:

¡Altas alamedas!)

¡Altas alamedas!

De lejos las miro..

¿Qué sombra entró en ellas?

¡Altas alamedas!

(El viento suspira:

¡Altas alamedas!) -ique sus ojos me vean!-, entré a su cuerpo.

-iQue sus ojos me vean!

Miro en la piedra

-ique sus ojos me vean!-,

las ramas que he perdido

-ique sus ojos me vean!-,

nacen por verla.

-iQue sus ojos me vean!

No obstante, el realce del estribillo se ha conseguido, además, minimizando el texto de la canción, buscando un equilibrio entre el número de versos del texto y el número de ocurrencias del estribillo; el estribillo cobra, así, prominencia.

El máximo exponente del estribillo como letanía en la obra lírica de Prados es sin duda "Letanía de la noche», de Tiempo. Veinte poemas en verso (I, 149): el poema está compuesto básicamente de dísticos, cuyo primer verso lo forma la palabra Noche, y el segundo verso es un sintagma nominal en aposición: «Noche,/ rosa negra/ con estambres/ de estrellas.// Noche,/ tintero de poetas.// Noche,/ parra embrujada.// Noche,/ colmena abierta.// Noche,/ nido de garzas.// Noche, manzana hueca [...]».

Hay otro virtuosismo, utilizado por Prados en diversas ocasiones, que podríamos llamar estribillo encadenado. El estribillo encadenado es el cantarcillo o estrofa que se repite, idéntico o con variaciones, en las distintas partes en que se estructura un poema. La composición simula una cadena de eslabones cuyo engarce formal es el estribillo. «Estampas del farero», de Poemas sueltos inéditos anteriores a 1930 (II, 753) y «Viaje», de Tiempo. Veinte poemas en verso (I, 175), constituyen unos magníficos ejemplos: 
Domingo recién planchado, con sombrero de ala nuevo.

El sol, pasador de oro

en la camisa del Tiempo...

...y la cometa

nadando

-pez de agua dulce-

en el cielo,

haciéndole la lazada

a la corbata del viento.

El barco quieto en el mar.

El sol bajo el olivar.

\section{2}

El sol,

dentro de un paréntesis.

Buscando su horario

un árbol.

Entre algodones

del viento

dos pájaros disecados.

En el arroyo

sereno,

sus dos reflejos ahogados.

El barco quieto en el mar.

El sol bajo el olivar.

\section{3}

Tres pájaros van volando

$\mathrm{y}$ el aire se va quebrando.

El gallo pinta paisajes

y el caracol plancha el huerto.
I

El mar de color de nácar.

El mapa tiembla de miedo mostrando sus frutas planas

y la rosa de los vientos

cae deshojada en el agua.

-Capitán,

se me ha perdido

mi único anillo

de plata-.

2

El mar de color de malva.

El corazón del marino

-tintero de tinta granacomo el tintero su pluma, tiene una flecha clavada.

-Capitán,

se me ha caído

mi álbum de firmas

al agua-.

3

El mar de color de malva.

El corazón del marino

tiene su aguja imantada.

-Capitán,

se te ha olvidado

dejar en tierra

una carta-.

En la página del mar

firma el sol

con tinta blanca.

(A la cintura del agua

el delantal de un reflejo.)

Sobre el umbral de la siesta, perezoso y soñoliento, junto al borde de las horas, sella el girasol al Tiempo.

El barco quieto en el mar.

El sol bajo el olivar. 
«Tres acertijos fáciles», de Mosaico, recogido en el Apéndice: Poemas inéditos (II, 712); «Tambores de sombra», de Río natural. Libro Primero. Dudas de abril, (II, 106); o "Arranques», en Jardín en medio, de La piedra escrita (II, 375), con estribillo embutido, son otros ejemplos igualmente representativos.

Una forma original, aunque escasamente empleada por Prados, es el estribillo que podríamos llamar diseminado: el cantarcillo ubicado en la cabeza del poema se repite en cada una de las estrofas no, como es habitual, en bloque, constituyendo una unidad autónoma, sino fragmentado. Así, en uno de los Poemas sueltos del exilio (II, 947), el estribillo inicial es desarticulado y sus líneas versales se diseminan en las cuatro estrofas simétricas que conforman el cuerpo del texto, intercalándose entre sus versos. El intercalado adopta un esquema alternante, respetando siempre el orden de sucesión de los versos del estribillo, que se repite idénticamente en todas las estrofas:

¡Mis ojos!

¡Que se me escapan!

¿Ya se fueron?...

Entre dos silencios

(¡mis ojos!)

llevaron al campo

¡que se me escapan!

mi cuerpo en mis brazos.

(¿Ya se fueron?)

Una campanada

(imis ojos!)

me abrió en dos silencios

(¡que se me escapan!)

y entré por mi cuerpo.

(¿Ya se fueron?)
Dentro de mí el campo

(¡mis ojos!)

me encuentro de nuevo...

(ique se me escapan!)

y entré a su silencio.

(¿Ya se fueron?)

Desnudo en el campo

(¡mis ojos!)

abierto en mis brazos

(ique se me escapan!)

se entregó mi cuerpo.

(¿Ya se fueron?)

¡Que se me escapan! 


\section{Conclusiones}

Dos de los rasgos de estilo de la poesía de Emilio Prados son, por un lado, la adopción constante de los modelos líricos tradicionales, conforme al gusto de la poesía neopopular contemporánea, y, por otro, la ruptura de los patrones convencionales: cuando Prados elige un forma métrica, tiende a quebrantarla en algún punto de la composición, con frecuencia en el cierre del discurso.

En las creaciones poéticas de estribillo, éste presenta una gran diversidad de formas de expresión: el estribillo con carácter envolvente o circular encabezando y cerrando el poema, con o sin elemento iterativo medial, el estribillo invariable o constante y el estribillo variable o con variantes (léxicas, sintácticas, gráficas...), el estribillo exento y el estribillo embutido o integrado en la estrofa, el estribillo alternante en poemas poliestróficos, el estribillo reforzado o dominante sobre el texto corto y el estribillo mínimo o de extensión breve, poemas de estribillo descabezados o sin cierre rematados con un estrambote, poemas con dos estribillos alternantes, etc.

\section{Bibliografía utilizada}

BAHER, Rudolf.: Manual de versificación española (1962). Madrid: Gredos, 1973.

CASTILLO JIMÉNEZ, José Luis del: «Las formas métricas tradicionales en Emilio Prados (Mínima muerte)». Revista de Literatura, 1985, XLVII, 93, pp. 129-138.

DEBICKI, A. P.: «Unos procedimientos sintácticos en la poesía de Emilio Prados», en Estudios de poesía española contemporánea (1968). Madrid: Gredos, 1981, pp. 352-365.

DOMÍNGUEZ CAPARRÓS, José: Métrica española. Madrid: Síntesis, 1993.

FRENK ALATORRE, Margit: Corpus de la antigua lírica popular hispánica (siglos XV a XVII). Madrid: Castalia, ${ }^{2} 1990$.

GARCÍA-PAGE, Mario: «Emilio Prados: el estribillo» (2003), en Poesía española contemporánea (siglo Xx). Ocho poetas, ocho estudios de lengua literaria. Lugo: Axac, 2009, pp. 53-74.

— «La repetición como sistema de cierre textual», en Manuel Casado Velarde y otros (eds.), Análisis del discurso: lengua, cultura, valores. 
Actas del I Congreso Internacional. Madrid: Arco/Libros, 2005, II, pp. $1325-1343$.

LÓPEZ, Ignacio-Javier: «Repetición e integración en la obra poética de Emilio Prados». Bulletin of Hispanic Studies, 1985, LXII, pp. 373-383.

LÓPEZ CASTRO, Antonio: «La poesía de Emilio Prados» (1988), en Poetas del 27. León: Universidad de León, 1993, pp. 267-322.

LUJÁN ATIENZA, Ángel Luis: «El estribillo y sus variantes en la poesía española del siglo xx. Notas sobre su caracterización y tipología», 2010 (manuscrito).

MORRÁS, María: «ZZéjeles o formas zejelescas? Observaciones para el estudio de un problema de historia literaria». La Corónica, 1988, XVIII, 1, pp. 52-75.

NAVARRO TOMÁS, Tomás: Métrica española. Reseña histórica y descriptiva (1956). Madrid: Guadarrama, 1972.

SÁNCHEZ ROMERALO, Agustín: El villancico. (Estudios sobre la lírica popular en los siglos XV y XVI). Madrid: Gredos, 1969 